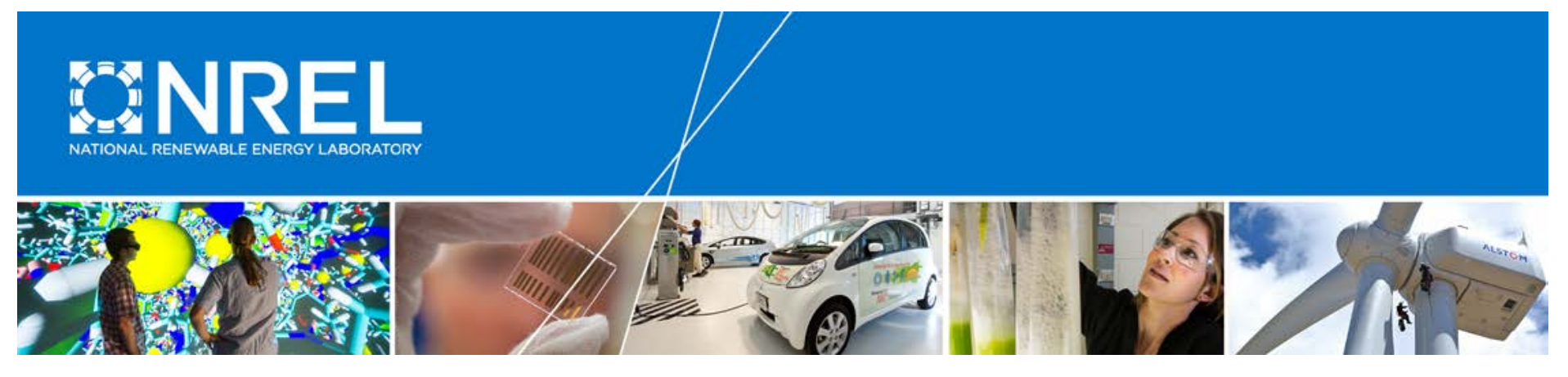

\title{
Developing High PV Penetration Cases for Frequency Response Study of U.S. Western Interconnection
}

\section{Preprint}

\author{
Jin Tan, Yingchen Zhang, Santosh Veda, \\ and Tarek Elgindy \\ National Renewable Energy Laboratory \\ Yilu Liu \\ University of Tennessee
}

Presented at the IEEE Green Technologies Conference Denver, Colorado

March 29-31, 2017

(C) 2017 IEEE. Personal use of this material is permitted. Permission from IEEE must be obtained for all other uses, in any current or future media, including reprinting/republishing this material for advertising or promotional purposes, creating new collective works, for resale or redistribution to servers or lists, or reuse of any copyrighted component of this work in other works.

NREL is a national laboratory of the U.S. Department of Energy Office of Energy Efficiency \& Renewable Energy Operated by the Alliance for Sustainable Energy, LLC

This report is available at no cost from the National Renewable Energy Laboratory (NREL) at www.nrel.gov/publications.

\section{Conference Paper}

NREL/CP-5D00-67737

April 2017

Contract No. DE-AC36-08G028308 


\section{NOTICE}

The submitted manuscript has been offered by an employee of the Alliance for Sustainable Energy, LLC (Alliance), a contractor of the US Government under Contract No. DE-AC36-08GO28308. Accordingly, the US Government and Alliance retain a nonexclusive royalty-free license to publish or reproduce the published form of this contribution, or allow others to do so, for US Government purposes.

This report was prepared as an account of work sponsored by an agency of the United States government. Neither the United States government nor any agency thereof, nor any of their employees, makes any warranty, express or implied, or assumes any legal liability or responsibility for the accuracy, completeness, or usefulness of any information, apparatus, product, or process disclosed, or represents that its use would not infringe privately owned rights. Reference herein to any specific commercial product, process, or service by trade name, trademark, manufacturer, or otherwise does not necessarily constitute or imply its endorsement, recommendation, or favoring by the United States government or any agency thereof. The views and opinions of authors expressed herein do not necessarily state or reflect those of the United States government or any agency thereof.

This report is available at no cost from the National Renewable Energy Laboratory (NREL) at www.nrel.gov/publications.

Available electronically at SciTech Connect http:/www.osti.gov/scitech

Available for a processing fee to U.S. Department of Energy and its contractors, in paper, from:

U.S. Department of Energy

Office of Scientific and Technical Information

P.O. Box 62

Oak Ridge, TN 37831-0062

OSTI http://www.osti.gov

Phone: 865.576.8401

Fax: 865.576.5728

Email: reports@osti.gov

Available for sale to the public, in paper, from:

U.S. Department of Commerce

National Technical Information Service

5301 Shawnee Road

Alexandria, VA 22312

NTIS http://www.ntis.gov

Phone: 800.553 .6847 or 703.605 .6000

Fax: 703.605.6900

Email: orders@ntis.gov 


\section{Developing High PV Penetration Cases for Frequency Response Study of U.S. Western Interconnection}

\author{
Jin Tan, Member, IEEE \\ Yingchen Zhang, Senior Member, IEEE \\ Santosh Veda, Member, IEEE \\ Tarek Elgindy, Member, IEEE \\ National Renewable Energy Laboratory (NREL) \\ Golden, Colorado, 80401, USA \\ (Yingchen.zhang@nrel.gov)
}

\author{
Yilu Liu, Fellow, IEEE \\ Department of Electrical Engineering \\ and Computer Science \\ University of Tennessee \\ Knoxville, TN, 37996, USA
}

\begin{abstract}
Recent large penetrations of solar photovoltaic (PV) generation and the inertial characteristics of inverterbased generation technologies have caught the attention of those in the electric power industry in the United States. This paper presents a systematic approach to develop test cases of high penetrations of PV for the Western Interconnection. First, to examine the accuracy of the base case model, the Western Electricity Coordinating Council (WECC) model is validated by using measurement data from synchronized phasor measurement units. Based on the 2022 Light Spring case, we developed four high PV penetration cases for the WECC system that are of interest to the industry: $5 \% \mathrm{PV}+\mathbf{1 5} \%$ wind, $25 \% \mathrm{PV}+15 \%$ wind, $45 \% \mathrm{PV}+15 \%$ wind, $65 \% \mathrm{PV}+15 \%$ wind. Additionally, a method to project $\mathrm{PV}$ is proposed that is based on collected, realistic PV distribution information, including the current and future $P V$ power plant locations and penetrations in the WECC system. Both the utility-scale PV plant and residential rooftop $P V$ are included in this study.
\end{abstract}

Keywords-WECC; high PV penetration; $P V$ projection; frequency response.

\section{INTRODUCTION}

In recent years, solar power technologies have been experiencing rapid development in the United States. Most states have committed to high renewable portfolio standards (RPS) in the near future $[1,2]$. For example, California is leading the goal to achieve $50 \%$ by 2030 , and most other U.S. states have RPS that require approximately 10\%-40\% of their annual electricity sold. Solar will be a main contributor to RPS according to the latest data on renewable generation installation. For example, in 2015 solar was the largest source (69\%) of RPS construction [1].

The SunShot Vision Study (DOE 2012) suggests that solar energy could satisfy approximately $14 \%$ of U.S. electricity demand by 2030 and $27 \%$ by 2050 [3]. To achieve these goals, significantly more installed capacity and instantaneous power penetration levels of solar should be considered for system operation because of solar generation's low capacity factor and high uncertainty.

Large-scale renewable deployment will bring challenges [4-8]; one is to ensure that the electric power system can operate reliably. Frequency response (FR) - the ability of the power system to stabilize and arrest frequency deviations following large, sudden mismatches between generation and

This work was primarily supported by the U.S. Department of Energy SunShot National Laboratory Multiyear Partnership (SuNLaMP) under award 30844 . load-has always been an important operational concern. Recent studies have shown that frequency response has been declining in both the Eastern and Western interconnections during the past several years [9-12]. In the future, with a high penetrations of solar photovoltaic (PV), more synchronous generators may be replaced by utility-scale or distributed PV resources. This may further exacerbate the frequency response of the grid because current PV generation normally operates at its maximum power output without the capability to provide frequency support, which can be provided by conventional generators.

A number of previous studies have examined the effects of PV on distribution systems. Most research efforts have focused on distribution systems because the installed PV is assumed to be small enough to have little effect on a transmission system. In recent years [13], however, driven by the SunShot Vision Study, the impact of high penetrations of PV on transmission systems has caught the attention of industry and academics. These studies have examined the impacts of high penetrations of renewable generation on transmission systems. Ref. [7] studied the impact of increased penetrations of $\mathrm{PV}$ on the static performance and transient stability of a large power system. Ref. [4] presented a comparative investigation of the effect of PV on system stability in Ontario's power system at different penetration levels. Ref. [14] investigated the potential contributions of variable-speed wind generation on the Eastern Interconnection system frequency regulation. Ref. [15] focused on studying the frequency response of the Californian system under high wind and solar conditions. The base case in this study considered instantaneous penetrations of wind and solar at penetration levels as high as $17 \%$ in the Western Electricity Coordinating Council (WECC) and 37\% in California.

Since 2010, the National Renewable Energy Laboratory (NREL) and General Electric (GE) have conducted phases of the Western Wind and Solar Integration Study with different focuses, including long-term operational and economic performance, frequency response and transient stability, and operation and control [16-18]. Ref. [16] investigated the WECC system's operation under scenarios of high wind, high solar, and a high mix. In this study, NREL's Regional Energy Deployment System (ReEDS) model [19] was used to site the wind and solar power plants for each scenario. Ref. [20] examined the Western Interconnection's transient stability and frequency response under high penetrations of 
instantaneous wind and solar. Based on the modified WECC 2022 Light Spring (2022LSP) power flow and dynamic simulation base case, a high renewable case and an extremely high renewable case were developed.

Most of the aforementioned studies showed that high penetrations of renewables can have diverse effects on system frequency response and transient response. Note several key points: 1) some high PV cases for the WECC studies are not actual representations of a larger, interconnected power system [7]. 2) Wind power is the dominant resource in the aforementioned studies in the mixed wind and solar cases $[9,11]$. 3) The method to locate PV sites throughout the large interconnection is either extremely simplified [7], [15] or based on the self-developed tool to which the public has no access $[16,18]$. For example, in [7], PV is added to only a portion of the system, and there is a relatively large amount of conventional generation and export to other areas; [15] divides the WECC into the areas of California and non-California, and the increase in penetration level of PV is based on a rule of thumb. It is therefore necessary to generate more realistic PV penetration scenarios based on current publicly available data.

The first step is to comprehensively prepare the scenarios, evaluation metrics, power flow models, and dynamic models; these are also the keys to ensuring a reliable case study of a realistic electric grid. Therefore, this paper has two main contributions: 1) it explores a systematic approach to developing cases of high penetrations of PV for a realistic bulk electric grid - the Western Interconnection-based on publicly accessible data; and 2) it developed reasonable cases of high penetrations of $\mathrm{PV}$, which include a case with $100 \%$ regional instantaneous penetration and a case of $80 \%$ renewable instantaneous penetration $(65 \% \mathrm{PV}+15 \%$ wind $)$ in the Western Interconnection based on the detailed model. To the best of our knowledge, this is the highest PV penetration case developed for the Western Interconnection.

This paper is organized as follows. Section II provides an overview of the metrics used for the frequency response study. In Section III, the Western Interconnection model is validated by measurement data and analyzed. Section IV discusses the approach to developing the high PV penetration cases based on various databases, e.g., National Solar Radiation Data Base (NSRDB) data, Solar Energy Industries Association (SEIA) report, RPS data sheet. Section V shows the distribution results, and Section VI concludes.

\section{Evaluation Metrics DeVelopment}

Setting a proper frequency response standard and metrics is essential for planning and operating an interconnection. To comprehensively investigate the frequency response of the U.S. interconnections, various frequency response metricswhich were adopted for the previous studies - have been summarized and extracted in this section. This work aligns with the objective of the North American Electric Reliability Corporation (NERC)'s Frequency Response Initiative to improve frequency response performance tracking by developing proper metrics and benchmarks [21].

The previous metrics can be roughly divided into three categories for different purposes: frequency evaluation metrics under abnormal operation, frequency evaluation metrics under normal operation, and system-level metrics.

\section{A. Frequency Evaluation Metrics: Abnormal Operation}

\section{1) Single-Event-Based Metrics}

Since 2000, NERC and other industry experts have worked on defining consistent criteria to evaluate frequency response [22]. Fig. 1 shows a measured frequency excursion caused by a loss of a generation in the U.S. Western Interconnection.

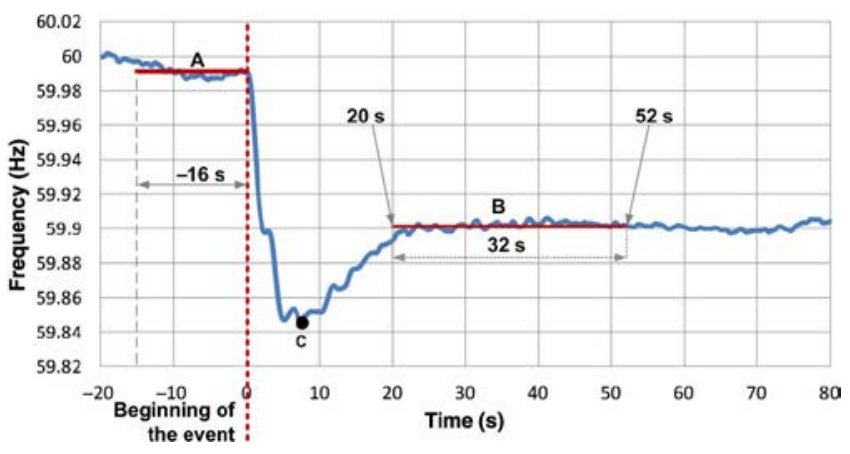

Figure 1. Description of BAL-003-1 frequency response metrics [9].

When an event happens, the inertia and primary frequency response of the system determines the lowest frequency $\left(f_{\mathrm{C}}\right)$, which should be kept above the setting of the underfrequency load shedding (UFLS). The settling frequency $\left(f_{\mathrm{B}}\right)$ is defined as the average frequency approximately from $\mathrm{t}=20$ seconds to $\mathrm{t}=52$ seconds after the event, which reflects the continued delivery of primary frequency response (PFR). The predisturbance frequency $\left(f_{\mathrm{A}}\right)$ is defined as the average frequency approximately from $\mathrm{t}=-16$ second to $\mathrm{t}=0$ second, which is also a significant contributor to the variability of frequency response [21]. In 2011, Lawrence Berkeley National Laboratory (LBNL) proposed a metric called nadir-based frequency response (NFR) to reflect the amount of generation needed to arrest the frequency and PFR to measure the power actually delivered by the primary frequency control at a specific time [23]. Based on previous technical studies during several decades, the discussion about the frequency response standard culminated in the approval of Standard BAL-003-1Frequency Response and Frequency Bias Setting Reliability Standard in 2014 by FERC [24]. Other metrics are summarized in Table I.

TABLE I. SUMMARY OF THE FREQUENCY RESPONSE METRICS

\begin{tabular}{|c|c|c|c|c|}
\hline & Symbol & Metric & Ref. & Definition \\
\hline A1 & $f_{\text {nadir }}$ & Frequency nadir (Hz) & $\begin{array}{c}{[9,21,} \\
23]\end{array}$ & $f_{C}$ \\
\hline A2 & $f_{\text {Pre }}$ & Predisturbance frequency & {$[21]$} & $f_{A}$ \\
\hline A3 & ROCOF & $\begin{array}{c}\text { Rate of change of frequency } \\
(\text { mHz/s) }\end{array}$ & {$[9]$} & $\frac{f_{A}-f_{C}}{t_{C}-t_{A}}$ \\
\hline A4 & $f_{\text {settling }}$ & Settling frequency (Hz) & {$[9,21]$} & $f_{B}$ \\
\hline A5 & N-FR & $\begin{array}{c}\text { Nadir-based frequency } \\
\text { response (MW/0.1Hz) }\end{array}$ & {$[23]$} & $\frac{\text { Power }_{\text {Lost }}}{f_{A}-f_{C}}$ \\
\hline A6 & FR & $\begin{array}{c}\text { Frequency response (MW/Hz) } \\
{[25]}\end{array}$ & $\frac{P o w e r_{\text {Lost }}}{f_{A}-f_{B}}$ \\
\hline A7 & PFR & $\begin{array}{c}\text { Primary frequency response at } \\
\text { T1 (MW) }\end{array}$ & {$[23]$} & Power $_{\text {deliver }}\left(T_{1}\right)$ \\
\hline
\end{tabular}


To eliminate the geographical dependency of the measurement, a way to measure the frequency is to use several measurements and then calculate the center of inertia (COI) frequency [26]. The system frequency was calculated from the frequency of each individual generator based on the concept of the COI frequency; the expression follows:

$$
f_{\text {sys }}=\frac{\sum_{i=1}^{N} H_{i} \cdot f_{i}}{\sum_{i=1}^{N} H_{i}}=\frac{1}{H_{T}} \sum_{i=1}^{N} H_{i} \cdot f_{i}
$$

where

$H_{\mathrm{i}}$ : inertia constant of the ith synchronous generator

$f_{\mathrm{i}}$ : the frequency of the ith synchronous generator.

\section{2) Statistical-Analysis-Based Metrics}

For the balancing authorities, frequency response performance is not a sufficient metric by which to judge compliance on a per-event basis. Normally, a minimum of 20-25 sample events are recommended to provide a stable measure of frequency response for an interconnection. A linear regression method is the preferred method for calculating the frequency response [21].

A minimum frequency performance criterion for each interconnection has been established as well; this is called the Interconnection Frequency Response Obligation (IFRO). The IFRO is designed to avoid the first stage of UFLS based on statistical analysis and an evaluation of historical fieldtrial data. For example, the IFRO of the Western Interconnection requires $-840 \mathrm{MW} / 0.1 \mathrm{~Hz}$ [21].

\section{B. Frequency Evaluation Metrics: Normal Operation}

During normal operation, standards and metrics are developed in BAL-003-1 for the balancing authority to evaluate the performance of managing the interchange power, area control error, and frequency during time frames of 1 minute or longer. The Control Performance Standard 1 requirement is based on 1-minute averages, and the Control Performance Standard 2 requirement is based on performance measured for 10 minutes. These averages are then further aggregated during the course of an entire year or month. Because this study mainly focuses on frequency response, descriptions about these metrics are omitted here.

\section{System-Level Metrics}

The frequency response is determined by the amount and types of the generation and load on the grid. Table II shows the critical factors of generation and load as they relate to frequency performance $[18,25]$.

\section{TABLE II. CASE SumMary Metrics}

\begin{tabular}{|c|c|c|}
\hline & Symbol & Metric Description \\
\hline $\mathrm{C} 1$ & $\mathrm{P}_{\text {gen }}$ & System generation $(\mathrm{GW})$ \\
\hline $\mathrm{C} 2$ & $\mathrm{P}_{\mathrm{GR}}$ & Generation of units with governor (GW) \\
\hline $\mathrm{C} 3$ & $\mathrm{P}_{\mathrm{mc}}$ & Capacity of the units with governor(GW) \\
\hline $\mathrm{C} 4$ & $\mathrm{P}_{\mathrm{hr}}$ & Headroom of units with governor (GW) \\
\hline $\mathrm{C} 5$ & $\mathrm{P}_{\mathrm{px}}$ & Generation of units without governor (GW) \\
\hline C6 & $\mathrm{P}_{\text {wind }}$ & Power generation of wind $(\mathrm{GW})$ \\
\hline $\mathrm{C} 7$ & $\mathrm{P}_{\text {solar }}$ & Power generation of solar(GW) \\
\hline $\mathrm{C} 8$ & $\mathrm{P}_{\text {load }}$ & System load (GW) \\
\hline C9 & $\mathrm{Kt}(\%)$ & Ratio of governor-responsive generation to total \\
\hline $\mathrm{C} 10$ & $\mathrm{H}_{\mathrm{sys}}$ & Equivalent system inertia (s) \\
\hline
\end{tabular}

The increased variable renewable generation will affect the efficacy of frequency control actions from several aspects: 1) reduce the system inertia, which can be reflected by $\mathrm{H}_{\text {sys }}$;2) potentially displace the synchronous generator with the governor, which can be reflected by $\mathrm{P}_{\mathrm{GR}}$; 3) potentially reduce the frequency control reserve, which can be reflected by $\mathrm{P}_{\mathrm{hr}}$; (4) affect the location of the primary frequency control reserves, which can be reflected by the interchange power of the tie-line.

In 2010, LBNL introduced a ratio as the metric Kt [27]: the lower the $\mathrm{Kt}$, the smaller the fraction of generation that will respond. The exact definition of $\mathrm{Kt}$ is not standardized, but a reasonable definition according to industry discussions is still warranted. In this paper, it is defined as follows:

$$
\mathrm{Kt}(\%)=\frac{P_{\mathrm{mc}}}{P_{\mathrm{mc}}+P_{\mathrm{px}}+P_{\text {wind }}+P_{\text {solar }}} \times 100
$$

The equivalent system inertia is:

$$
H_{\text {sys }}=\frac{K \cdot E .}{\operatorname{SUM}\left(V A_{\text {base }}\right)}
$$

where:

$$
K . E .=\sum_{i=1}^{n} H_{i} \times V A_{\text {base } \_} i
$$

$H_{\mathrm{i}}$ : inertia constant of the ith synchronous generator [s] $V A_{\text {base } \mathrm{i}}$ : rating of the ith synchronous generator [MVA] $V A_{\text {base }}$ : total online rating of the grid [MVA]

$K . E$. : kinetic energy at the rated speed $[\mathrm{MW} \cdot \mathrm{s}]$.

The metrics introduced here are developed to provide a tool to guide and gauge the impact of renewables on frequency response and operation of the grid. Different metrics can be flexibly chosen, adjusted, and added according to the different purposes of the study.

\section{MODEL VALIDATION AND DEVELOPMENT}

Accurate dynamic modeling is important for power system dynamic simulations and frequency response analysis. Following the 1996 blackouts in the western United States, WECC updated, validated, and calibrated its operation and planning models. WECC base cases have been recognized for their consistency and accuracy in general.

Because this paper focuses on developing future scenarios of high penetrations of solar for a frequency response study in WECC, a base case with a significant amount of planned renewable generators as well as low loading levels is an ideal benchmark for this development. The WECC 2022 Light Spring case was used as the base case for multiple studies of high renewable penetration levels and has the most current available renewable generation in the low-load system [8]; therefore, this case is used as the base case for the WECC study in this paper.

\section{A. Model Validation Using Synchrophasor Frequency Measurement}

To ensure the accuracy of the dynamic model of the base case, a sanity check is suggested to be applied by comparing the dynamic frequency response of the adopted WECC model to the FNET/GridEye frequency measurement data [28]. Although it is impossible to check the accuracy of the 
future scenario model by using current year measurements, it is reasonable to compare light spring cases in recent years to the FNET/GridEye recording for accuracy with the knowledge that the future planning cases are based on current system structures.

Four generation trip events that occurred in spring 2015 are used for the validation; these are shown in Table III.

TABLE III. EVENTS AND ESTIMATED AMOUNT

\begin{tabular}{|c|c|c|c|}
\hline Event & Date & Time (UTC) & $\begin{array}{c}\text { Estimated Generation } \\
\text { Trip (MW) }\end{array}$ \\
\hline $\mathrm{A}$ & $03 / 03 / 2015$ & $22: 24: 50$ & 783.5 \\
\hline $\mathrm{B}$ & $04 / 05 / 2015$ & $19: 57: 52$ & 805.0 \\
\hline $\mathrm{C}$ & $04 / 26 / 2015$ & $17: 53: 23$ & 605.0 \\
\hline $\mathrm{D}$ & $05 / 06 / 2015$ & $02: 00: 23$ & 715.0 \\
\hline
\end{tabular}

Because WECC did not publish the 2015 light spring case, the simulations are conducted by comparing the 2016 light spring case to the FNET/GridEye measurements. The FNET/GridEye frequency measurement data are selected from six different locations. The fault locations and generation trip amounts estimated by FNET/GridEye are used to decide the simulation scenarios. One test case is given in this section as an example, as shown in Fig. 2.
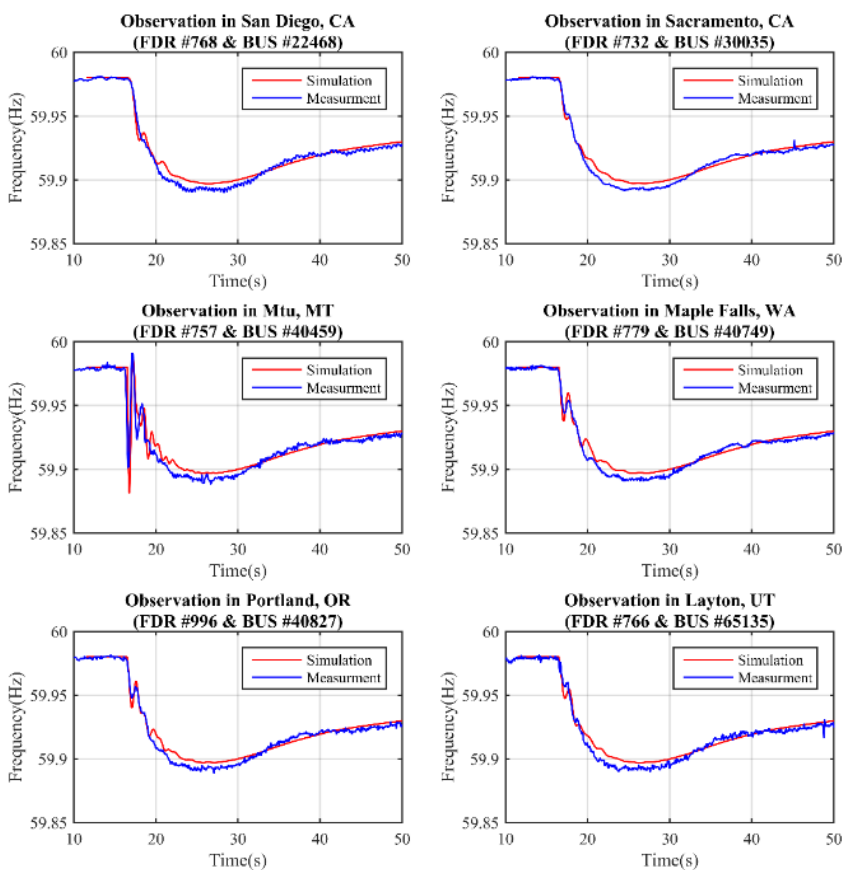

Figure 2. WECC model sanity check results

Fig. 2 shows that the simulated frequency response curves match well with the actual measured curves. Further, the frequency oscillation can be observed at FDR \#757, which is located in Montana. In the simulation, those oscillations are replayed. In particular, the first- and second-swing frequencies are accurately captured by the simulation. This means that this WECC model can truly reflect the frequency response dynamics of the WECC system during the event. This proves that the validated model has high fidelity.

\section{B. Base Case Overview}

The 2022 Light Spring case was developed to look at a high-renewables future from the WECC planning perspective; this includes wind and solar build-out. The renewable penetrations in this case are intended to be consistent with state RPS requirements in 2022.

A detailed understanding of the type of generation in the simulations is critical to gain insight into the effects of increased variable renewable generation. The 2022 Light Spring case is modeled at a very detailed level with more than 19,000 buses and more than 4,000 generators. It contains 21 areas, 424 zones, and 492 owners. Each type of power plant has corresponding dynamic models, including generator, exciter, and turbine governor models; these can vary widely because of the diversity in power plant configurations. Fig. 3 and Fig. 4 show the types and numbers of the generator dynamic models and prime mover models in the 2022 Light Spring case.

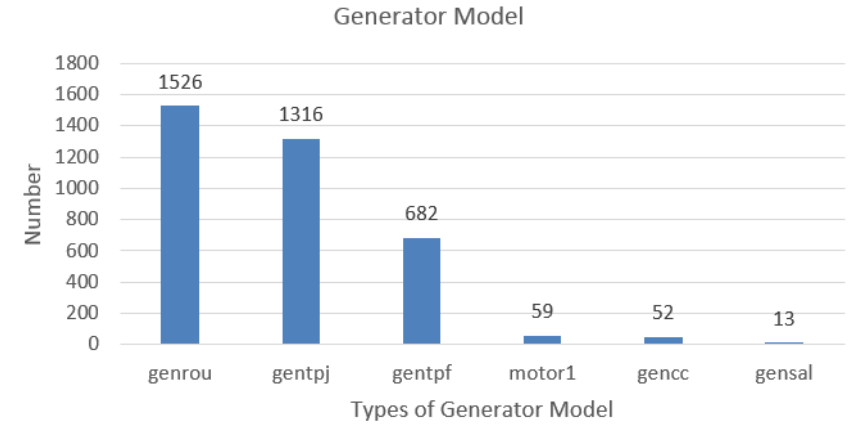

Figure 3. Number of generator models in the WECC 2022 Light Spring case.

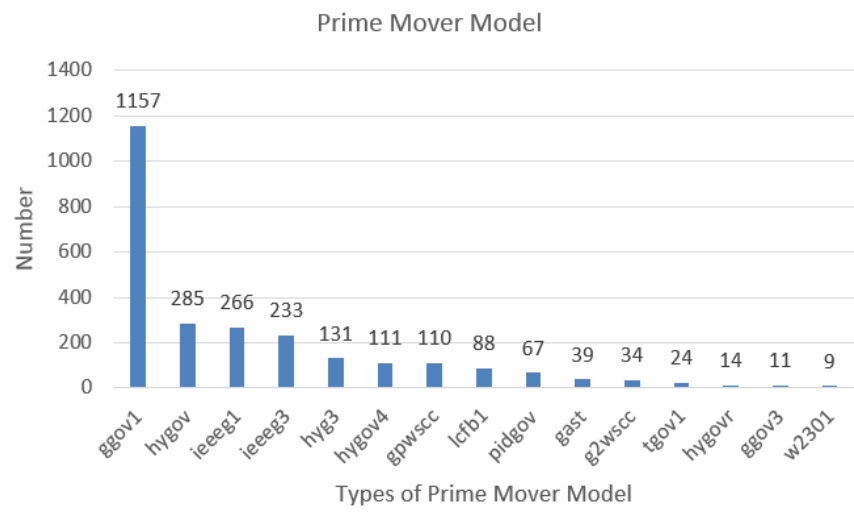

Figure 4. Number of prime mover models in the WECC 2022 Light Spring case.

A comparison of Fig. 3 to Fig. 4 shows that not all the synchronous generators are installed with governor models, which means that not all the synchronous generators can provide frequency response control. In reality, relatively few steam units provide governor response [25]. Nuclear power plants usually do not provide governor response because it is normally used to support the base load. Frequency response for the bulk system is mainly provided by hydropower, combined-cycle, and gas turbine generators.

Note that the dynamic model for each generator category, especially for the wind and solar units, needs close scrutiny. Because the dynamic behavior of wind and solar power plants is substantially different from that of thermal and hydro plants, it is important that the estimated models have the correct basic dynamic characteristics. In this case, wind power plants are modeled by Type 1, Type 2, Type 3, and Type 4 wind generation models and Type 3 and Type 4 GE wind turbine 
models. Solar units are modeled by Type 4 or GE Type 4 wind generation models without the turbine models. All synchronous machines will provide inertial response. Wind and solar will not provide frequency response in this case.

Table IV summarizes the instantaneous output and penetration level of the total generation, load, wind and PV generation.

TABLE IV.

SuMmARY OF GENERATION AND LOAD IN WECC 2022 Light SPRING CASE

\begin{tabular}{|c|c|c|}
\hline & Capacity & P $_{\text {gen }}$ \\
\hline WECC System Total (MW) & 312438 & 117238 \\
\hline Load (MW) & N/A & 112990 \\
\hline Wind Power & 26323 & 16464 \\
\hline Wind Power Penetration & $8.4 \%$ & $13.9 \%$ \\
\hline PV (MW) & 1838 & 1347 \\
\hline PV Penetration (\%) & $0.6 \%$ & $1.1 \%$ \\
\hline
\end{tabular}

Table IV shows that the total generation in the 2022 Light Spring case is $117 \mathrm{GW}$; wind power is the largest renewable resource, at approximately $13.9 \%$ instantaneous penetration; and $\mathrm{PV}$ is a small portion of the renewables, at only $1.1 \%$ instantaneous penetration.

\section{SCENARIO DEVELOPMENT}

The goal of this section is to collect realistic PV distribution information, including the current PV power plant location and penetration and future PV levels and locations in the WECC system. This information can be further used to develop a realistic baseline of the power system and different high-penetration scenarios based on the 2022 Light Spring case. In addition, to project PV distribution by states/areas, the collected PV resource data are used, including rooftop PV and utility-scale PV resource potential. After the generation composition is altered, the test cases are initialized to ensure that they are at steady state. This ensures that the loadgeneration balance has been achieved and that the test cases can be used for further analysis.

\section{A. General Scenario}

Based on the survey of 14 industrial participators from electric utilities, national labs, and research institutes from among all three U.S. interconnections, the to-be-developed scenarios are suggested in Table V.

TABLE V. SCENARIOS OF WIND AND PV CAPACITY AND INSTANTANEOUS PENETRATION IN WECC

\begin{tabular}{|c|c|c|c|}
\hline Scenario & $\begin{array}{c}\text { Wind } \\
\text { Instantaneous } \\
\text { Penetration }\end{array}$ & $\begin{array}{c}\text { PV } \\
\text { Instantaneous } \\
\text { Penetration }\end{array}$ & $\begin{array}{c}\text { PV Power } \\
\text { Output (GW) }\end{array}$ \\
\hline 2022 LSP & $14 \%$ & $1 \%$ & 1.3 \\
\hline $20 \%$ RIP & $15 \%$ & $5 \%$ & 5.9 \\
\hline $40 \%$ RIP & $15 \%$ & $25 \%$ & 29.4 \\
\hline $60 \%$ RIP & $15 \%$ & $45 \%$ & 52.8 \\
\hline $80 \%$ RIP & $15 \%$ & $65 \%$ & 76.3 \\
\hline \multicolumn{3}{|c|}{ RIP: renewable instantaneous penetration } \\
\hline
\end{tabular}

In summary, the instantaneous penetration level of wind power is maintained at $15 \%$ in four PV penetration scenarios, and the instantaneous penetration level of PV is $5 \%, 25 \%$, $45 \%$, and $65 \%$. The total renewable instantaneous penetration level in WECC reaches $20 \%, 40 \%, 60 \%$, and $80 \%$. A regional level of $100 \% \mathrm{PV}$ is also suggested to be built because of strong interest from some electric utilities.

\section{B. PV Distribution Projection for WECC}

\section{1) Data Resource for PV Distribution}

In April 2016, SEIA updated a list of major solar projects in the United States for informational purposes only [29]. The information in this list was gathered from public announcements of solar projects in the form of company press releases, news releases, and, in some cases, conversations with individual developers.

The NSRDB is a NREL-developed and publicly available database. It is a collection of meteorological and solar irradiance data sets for the United States and a growing list of international PV power plant locations. The NSRDB compiled some information from the SEIA database with some additions from independent NREL research and generated a location map of operational, utility-scale PV projects in the United States [30]. Some data resources used for PV projection in WECC are summarized in Table VI.

TABLE VI.

SuMmary of DATA RESOURCE FOR WECC PV Distribution PROJECTION

\begin{tabular}{|c|c|c|}
\hline $\begin{array}{c}\text { Data } \\
\text { Resource }\end{array}$ & Description & Usage \\
\hline NSRDB Data & $\begin{array}{l}\text { Estimated PV power } \\
\text { data based on average } \\
\text { annual direct normal } \\
\text { irradiance }\end{array}$ & $\begin{array}{l}\text { - To build out utility-scale } \\
\text { PV at the state level } \\
\text { - As a reference for PV } \\
\text { location and distribution } \\
\text { in different states. }\end{array}$ \\
\hline $\begin{array}{l}\text { WECC } 2022 \\
\text { LSP Base } \\
\text { Case }\end{array}$ & $\begin{array}{l}\text { Load and generation } \\
\text { for different areas and } \\
\text { renewables location and } \\
\text { penetration }\end{array}$ & $\begin{array}{l}\text { - Provides current PV } \\
\text { penetration and } \\
\text { distribution of the } 2022 \\
\text { LSP base case } \\
\text { - As a reference for the } \\
\text { maximum penetration in } \\
\text { each area and future } \\
\text { dynamic simulations. }\end{array}$ \\
\hline SEIA's Data & $\begin{array}{c}\text { Current capacities and } \\
\text { locations for utility-scale } \\
\text { PV project in different } \\
\text { states }\end{array}$ & $\begin{array}{l}\text { - Real data as a reference } \\
\text { for the minimum } \\
\text { installed capacity and } \\
\text { penetration. }\end{array}$ \\
\hline $\begin{array}{c}\text { RPS } 2022 \\
\text { Data Sheet }\end{array}$ & $\begin{array}{l}\text { RPS } 2022 \text { goals by state } \\
\text { and type, capacity, } \\
\text { location, and project } \\
\text { process of renewable } \\
\text { projects. }\end{array}$ & $\begin{array}{l}\text { - As a reference for future } \\
\text { PV distribution in } \\
\text { different states } \\
\text { - To improve the dynamic } \\
\text { model in future studies. }\end{array}$ \\
\hline
\end{tabular}

SEIA stated that in 2014 new installed solar PV capacity in the United States was 6,200 MW, with 3,900 MW of utility-scale PV, 1,000 MW of commercial PV, and 1,200 MW of residential PV [31]. This is approximately $63 \%$ utility-scale and 37\% commercial/residential PV. The bulk of the PV (79\%) has been in the West, with 17\% in the East. So it is fair to build out a PV scenario that is $60 \%$ utilityscale and $40 \%$ rooftop PV.

\section{2) Renewable Siting Method}

This study proposes using the PV resource data as indicators to distribute solar build-out by states/areas. Rooftop PV and utility-scale PV are distinguished because of the significant difference in technique and installing conditions and the methods to estimate their technical potentials. We use NSRDB data to decide the future utilityscale PV distribution, and results' from NREL's previous work are adopted to distribute the future rooftop PV [32]. Several assumptions were made for the study: 
1. This study was not a transmission planning study. To reduce the impact of transmission-related issues, the renewable penetration level was increased without modifying the interchange power flow among the WECC areas.

2. According to the analysis in Section IV-B-1 of historical data, all PV scenarios comprise $60 \%$ utility-scale PV and $40 \%$ rooftop $\mathrm{PV}$.

3. The 2022 Light Spring base case has 21 areas in the model of the positive sequence load flow analysis software. To maintain consistency, the statewide solar technical potential data will be manually and roughly distributed to the areas according to the geographic locations.

4. The minimum PV capacity was aligned with SEIA's data, and the maximum PV capacity was aligned with the rooftop PV technical potential and utility-scale technical potential, respectively.

Because the purpose of this study is to investigate the frequency response of WECC, and frequency is a systemwide indicator, our effort is mainly to make high PV scenarios more realistic in terms of resource distribution in different areas. The initial renewable penetration condition in the 2022 Light Spring base case was used as a starting point. The rooftop PV was distributed to each area proportional to the rooftop PV technical potential. In the same manner, the utility-scale PV was proportionally projected according to utility-scale PV technical potential, which was estimated by using NSRDB data. Some realistic resource constraints and operational constraints were considered, such as the maximum and minimum installed PV capacity in each area and the exchange of power flow among the areas. If a certain penetration level could not be fulfilled with all constraints, partial constraints were relaxed until that penetration level was reached. The flowchart of this process is shown in Fig. 5.

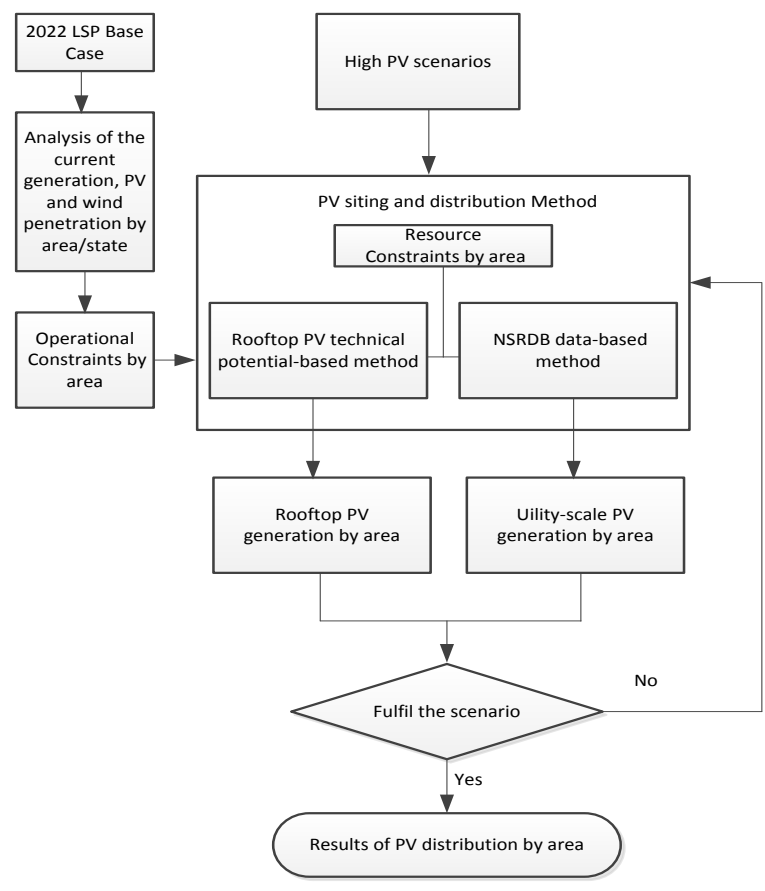

Figure 5. Flowchart of PV distribution projection in WECC.

\section{Rooftop PV Technical Potential-Based Method}

The rooftop PV technical potential data are from a recent NREL report [32]; the report provides a detailed data-driven analysis of U.S. (at the national, state, and ZIP code level) rooftop PV availability and technical electricity generation potential. This study provides a realistic estimation of future rooftop PV installation. According to the report, the total estimated technical potentials for rooftop PV by state are shown in Table VII.

TABLE VII. TOTAL ESTIMATED TECHNICAL POTENTIAL (ALL BuILDINGS) FOR ROOFTOP PV AND UTILITY-SCALE PV By STATE

\begin{tabular}{|c|c|c|c|c|c|c|c|}
\hline & State & $\mathbf{C A}$ & $\mathbf{A Z}$ & UT & $\mathrm{CO}$ & NM & WA \\
\hline \multirow{3}{*}{$\mathrm{R}$} & $\begin{array}{l}\text { Installed Capacity } \\
\text { Potential (GW) }\end{array}$ & 129 & 16 & 7 & 16 & 6 & 22 \\
\hline & $\begin{array}{l}\text { Population (in } \\
\text { Millions) }\end{array}$ & 39 & 6.8 & 3.0 & 5.5 & 2.1 & 7.2 \\
\hline & Percentage (\%) & 56 & 7 & 3 & 7 & 2.7 & 9.9 \\
\hline \multirow[t]{3}{*}{$\mathrm{U}$} & $\begin{array}{l}\text { Total Energy } \\
(1,000 \mathrm{GWh})\end{array}$ & 164 & 122 & 91 & 105 & 128 & 61 \\
\hline & Percentage (\%) & 13.6 & 10.1 & 7.5 & 8.7 & 10.6 & 5.1 \\
\hline & State & $\mathbf{N V}$ & WY & ID & MT & OR & \\
\hline \multirow{3}{*}{$\mathrm{R}$} & $\begin{array}{l}\text { Installed Capacity } \\
\text { Potential (GW) }\end{array}$ & 8.70 & 1.70 & 4.70 & 3.20 & 14.10 & \\
\hline & $\begin{array}{l}\text { Population (in } \\
\text { Millions) }\end{array}$ & 2.9 & 0.6 & 1.7 & 1.0 & 4.0 & \\
\hline & Percentage (\%) & 3.8 & 0.7 & 2.0 & 1.4 & 6.1 & \\
\hline \multirow[t]{2}{*}{$\mathrm{U}$} & $\begin{array}{l}\text { Total Energy } \\
(1,000 \mathrm{GWh})\end{array}$ & 121 & 99 & 82 & 139 & 94 & \\
\hline & Percentage (\%) & 10.0 & 8.2 & 6.8 & 11.5 & 7.8 & \\
\hline \multicolumn{8}{|c|}{ R: Rooftop PV; U: Utility-scale PV } \\
\hline
\end{tabular}

\section{NSRDB Data-Based Method}

The NSRDB data set provides the estimated PV average power that is converted from the irradiance data by considering geographic factors (e.g., site latitude, longitude, elevation), weather factors (e.g., ambient temperature and wind speed), and PV cells technology. The reliable data resource can represent a state's typical solar generation for the whole year (for example, see Arizona, California, Colorado, and Idaho in Fig. 6), which can be used for utilityscale PV development.
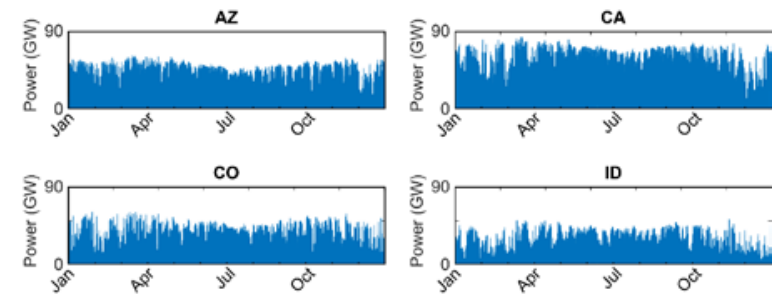

Figure 6. PV potential estimation in the form of power (2014).

In this study, we use one-year PV power data by states to roughly estimate the technical potential of the utility-scale PV shown in Table VII. Note that this estimation is from the perspective of the solar resource, and some other factors can be considered to improve the accuracy of the technical potential estimation of the utility-scale PV, such as potential land use and transmission build-out.

\section{RESUlTS AND Discussions}

The projection results of instantaneous penetration level and power output of rooftop PV, utility-scale PV, and wind by area in WECC are shown in Fig. 7. 

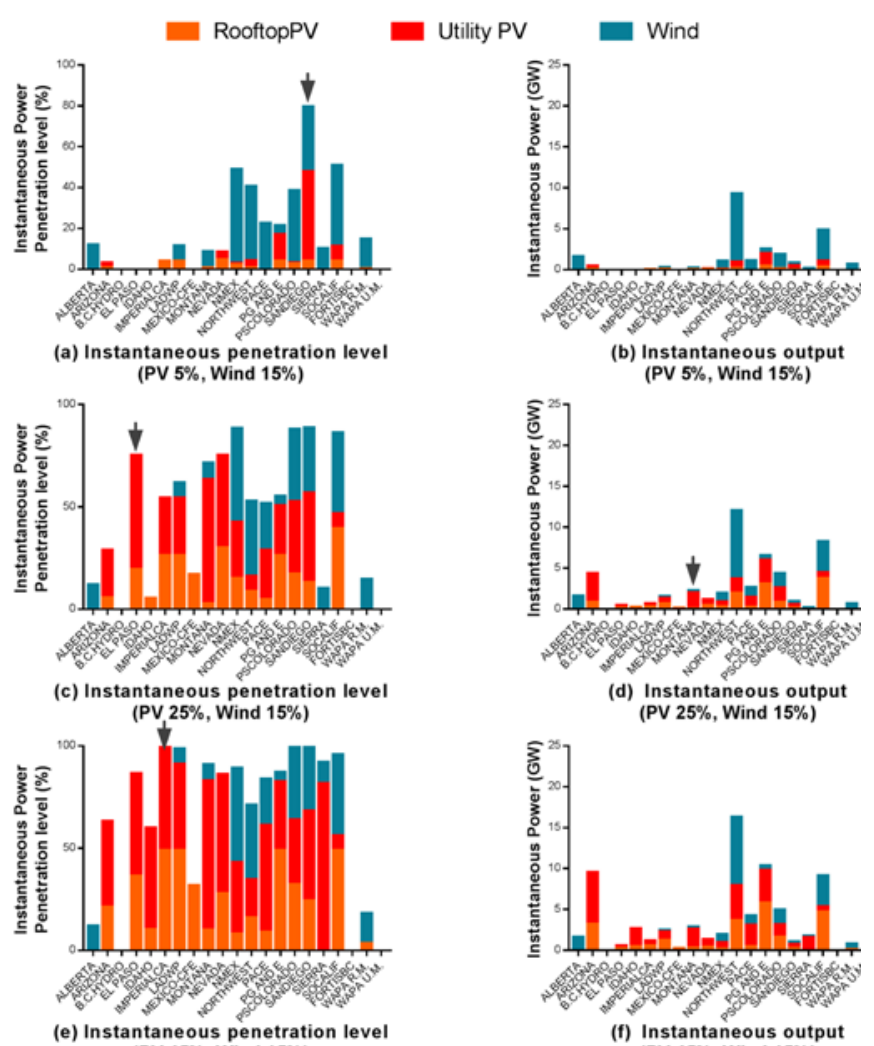
(PV 45\%, Wind 15\%)
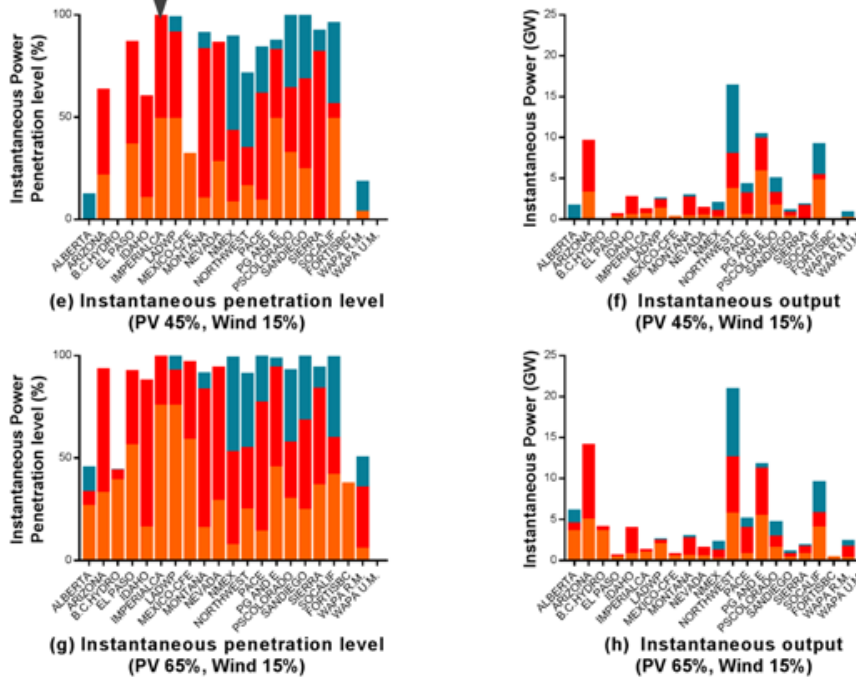

Figure 7. PV and wind penetration level and instantaneous power output for each area in WECC.

The bar plot shows the wind (blue), rooftop PV (orange) and utility-scale PV (red), respectively. A summary of the PV distribution in WECC is also given below:

\section{$20 \%$ Renewables Scenario (5\% PV)}

- In this case, the SANDIEGO area (located in California) has the highest regional instantaneous PV penetration level and renewable penetration level, which are $47.84 \%$ and $79.54 \%$, respectively (see the arrow in Fig.7 (a)). One of the main reasons for this is because the original $\mathrm{PV}$ and renewable penetration level in this area is already as high as $43.73 \%$ and $75.43 \%$ in the 2022 Light Spring base case.

- The difference between the pattern of penetration level and power output can be observed. For example, SANDIEGO is a relative small area with a low amount of generation, even though it has a high penetration level of renewables.

- $\quad$ To fulfil the $15 \%$ wind penetration level, we increase the NORTHWEST area's instantaneous wind power output to $8350.76 \mathrm{MW}$ according to [20].
40\% Renewables Scenario (25\% PV)

- Rooftop PV and utility-scale PV increased significantly compared to the $20 \%$ renewables scenario.

- SOCALIF (California), PG\&E (California), and ARIZONA are the main contributors to this.

- EL PASO's (Texas) regional PV penetration level reaches as high as $75 \%$ in this case (see the arrow in Fig.7 (c)).

- The main PV contributors in MONTANA are utility-scale PV (see the arrow in Fig.7 (d)).

\section{$60 \%$ Renewables Scenario (45\% PV)}

- As the PV penetration level increases further, some areas will hit the upper boundary of the maximum for the area's generation when we distribute PV proportionally according to the resource-based method. Some modifications were applied in this case to keep the interchange among areas unchanged.

- The regional renewable penetration level in six areas reaches 90\%: SANDIEGO (California), IMPERIALCA (California), PSCOLORADO (Colorado), LADWP (California), SOCALIF (California), and SIERRA (Nevada).

- IMPERIALCA (California) reaches a 100\% PV penetration level (see the arrow in Fig.7 (e)).

- California and Arizona are the main contributors to increased PV generation.

\section{$80 \%$ Renewables Scenario (65\% PV)}

- In this case of extremely high PV penetration, we need to artificially increase the PV in the northern states to fulfill the total PV penetration goal. For example, northern states such as B.C.HYDRO and ALBERTA need more installed PV, which breaks the constraints of the ratio of PV in different states.

- The penetration levels of renewables in 15 states are more than $90 \%$.

- California, Arizona, and the Pacific Northwest are the main contributors to the increased PV generation.

\section{CONCLUSION}

This paper has summarized useful metrics for frequency response, validated the WECC model with the measured frequency data, and developed a systematic method to project the PV in WECC by area.

Among the proposed scenarios, the highest wind and solar instantaneous penetrations in the Western Interconnection can reach $80 \%$, composed of $65 \% \mathrm{PV}$ and $15 \%$ wind. A $100 \%$ regional PV penetration case is created in IMPERIALCA in California. The total ratio of the utilityscale PV and the rooftop PV in WECC is 6:4. A practical method to distribute newly added PV by area is proposed based on realistic PV projects from various publicly accessible data resources. Rooftop PV and utility-scale PV are distinguished and projected based on their technical 
potential by states/areas. All the constraints of the distribution method can be calculated and achieved based on NREL-published NSRDB data and reports.

The result shows that California and Arizona are the main contributors to increased PV generation. To fulfil the scenario of extremely high PV penetration ( $80 \%$ in WECC), the northern areas, such as B.C.HYDRO and ALBERTA, need to provide additional PV generation. Future power systems with low rotational inertia will make frequency control and power system operation more challenging. The work presented in this paper will be used for a follow-on study funding by the U.S. Department of Energy on the "Frequency Response Assessment and Improvement of Western Interconnection because of High Penetrations of Photovoltaic Generation."

\section{REFERENCES}

[1] G. Barbose, "US Renewables Portfolio Standards: 2016 Annual Status Report," Lawrence Berkeley National Laboratory (LBNL), Berkeley, CA (United States)2016.

[2] R. Shah, N. Mithulananthan, R. Bansal, and V. Ramachandaramurthy, "A review of key power system stability challenges for large-scale PV integration," Renewable and Sustainable Energy Reviews, vol. 41, pp. 1423-1436, 2015.

[3] G. Brinkman, P. Denholm, E. Drury, E. Ela, T. Mai, R. Margolis, et al., "Grid modeling for the SunShot vision study," Contract, vol. 303, pp. 275-3000, 2012.

[4] B. Tamimi, C. Cañizares, and K. Bhattacharya, "System stability impact of large-scale and distributed solar photovoltaic generation: The case of Ontario, Canada," IEEE Transactions on Sustainable Energy, vol. 4, pp. 680-688, 2013.

[5] C. Seneviratne and C. Ozansoy, "Frequency response due to a large generator loss with the increasing penetration of wind/PV generation-A literature review," Renewable and Sustainable Energy Reviews, vol. 57, pp. 659-668, 2016.

[6] H. Jiang, J. J. Zhang, W. Gao, and Z. Wu, "Fault detection, identification, and location in smart grid based on data-driven computational methods," IEEE Transactions on Smart Grid, vol. 5, pp. 29472956, 2014.

[7] S. Eftekharnejad, V. Vittal, G. T. Heydt, B. Keel, and J. Loehr, "Impact of increased penetration of photovoltaic generation on power systems," IEEE transactions on power systems, vol. 28, pp. 893901, 2013.

[8] J. Tan, Y. Zhang, I. Krad, V. Gevorgian, and E. Ela, "Investigating Power System Primary and Secondary Reserve Interaction under High Wind Power Penetration Using Frequency Response Model," presented at the 2015 Grid of the Future Symposium, Chicago, Oct. 12-13, 2015.
[9] V. Gevorgian, Z. Yingchen, and E. Ela, "Investigating the Impacts of Wind Generation Participation in Interconnection Frequency Response," Sustainable Energy, IEEE Transactions on, vol. 6, pp. 1004-1012, 2015.

[10] S. Z. You, X ; Liu, Yong; Su, Y; Liu, Yilu; Hadley, $S$ "Impact of High PV Penetration on U.S. Eastern Interconnection Frequency Response," presented at the submitted to Power \& Energy Society General Meeting, Chicago, 2017.

[11] M. J. Till, Y. Liu, Y. Liu, M. Patel, and T. King, "Frequency response of the Eastern Interconnection due to increased wind generation," in 2014 IEEE PES General Meeting| Conference \& Exposition, 2014, pp. 1-5.

[12] J. W. Ingleson and E. Allen, "Tracking the Eastern Interconnection frequency governing characteristic," in IEEE PES General Meeting, 2010, pp. 1-6.

[13] F. Ding, B. Mather, and P. Gotseff, "Technologies to increase PV hosting capacity in distribution feeders," in Power and Energy Society General Meeting (PESGM), 2016, 2016, pp. 1-5.

[14] Y. Liu, J. R. Gracia, T. J. King, and Y. Liu, "Frequency Regulation and Oscillation Damping Contributions of Variable-Speed Wind Generators in the US Eastern Interconnection (EI)," IEEE Transactions on Sustainable Energy, vol. 6, pp. 951-958, 2015.

[15] N. Miller, M. Shao, S. Venkataraman, C. Loutan, and M. Rothleder, "Frequency response of California and WECC under high wind and solar conditions," in 2012 IEEE Power and Energy Society General Meeting, 2012, pp. 1-8.

[16] D. Lew, G. Brinkman, E. Ibanez, B. Hodge, and J. King, "The western wind and solar integration study phase 2," Contract, vol. 303, pp. 275-3000, 2013.

[17] G. Energy, "Western wind and solar integration study," Citeseer2010.

[18] N. Miller, M. Shao, S. Pajic, and R. D'Aquila, "Western wind and solar integration study phase 3frequency response and transient stability," Contract, vol. 303, pp. 275-3000, 2014.

[19] W. Short, P. Sullivan, T. Mai, M. Mowers, C. Uriarte, N. Blair, et al., "Regional energy deployment system (ReEDS)," Contract, vol. 303, pp. 275-3000, 2011.

[20] N. Miller, M. Shao, S. Pajic, and R. D'Aquila, "Western Wind and Solar Integration Study Phase 3--Frequency Response and Transient Stability (Report and Executive Summary)," National Renewable Energy Laboratory (NREL), Golden, CO.2014.

[21] NERC, "Frequency Response Initiative Report," 2012.

[22] NREC. Frequency Response Standard Whitepaper [Online].

Available: http://www.nerc.com/docs/oc/rs/Frequen cy_Response_White_Paper.pdf 
[23] J. H. Eto, "Use of frequency response metrics to assess the planning and operating requirements for reliable integration of variable renewable generation," Lawrence Berkeley National Laboratory, 2011.

[24] NERC. BAL-003-1 Frequency Response and Frequency Bias Setting Reliability Standard [Online].

Available: http://www.nerc.com/pa/Stand/Reliabilit y\%20Standards/BAL-003-1.1.pdf

[25] N. W. Miller, M. Shao, R. D'aquila, S. Pajic, and K. Clark, "Frequency Response of the US Eastern Interconnection Under Conditions of High Wind and Solar Generation," in 2015 Seventh Annual IEEE Green Technologies Conference, 2015, pp. 21-28.

[26] Y. Zhang, J. Bank, E. Muljadi, Y.-H. Wan, and D. Corbus, "Angle instability detection in power systems with high-wind penetration using synchrophasor measurements," IEEE Journal of Emerging and Selected Topics in Power Electronics, vol. 1, pp. 306-314, 2013.

[27] J. Undrill, "Power and Frequency Control as it Relates to Wind-Powered Generation," Lawrence Berkeley National Laboratory2010.
[28] Y. Zhang, P. Markham, T. Xia, L. Chen, Y. Ye, Z. $\mathrm{Wu}$, et al., "Wide-area frequency monitoring network (FNET) architecture and applications," IEEE Transactions on smart grid, vol. 1, pp. 159$167,2010$.

[29] SEIA. (2016). Major Solar Projects in the United States:Operating, Under Construction, or Under Development.

Available: http://www.seia.org/sites/default/files/res ources/Major\%20Projects\%20List\%2020160504_0. pdf

[30] National Solar Radiation Data Base. Available: https://maps.nrel.gov/nsrdb-viewer/

[31] SEIA. (2015). U.S. Installs $6.2 \mathrm{GW}$ of Solar PV in 2014, Up 30\% Over 2013. Available: http://www.seia.org/news/us-installs-62gw-solar-pv-2014-30-over-2013

[32] P. Gagnon, R. Margolis, J. Melius, C. Phillips, and R. Elmore, "Rooftop Solar Photovoltaic Technical Potential in the United States: A Detailed Assessment," Rep. No. NREL/TP-6A20-65298). Retrieved March, vol. 30, p. 2016, 2016. 